Научная статья

УдК 372.853

DOI https://doi.org/10.24866/VVSU/2073-3984/2021-4/223-230

О.Е. Кадеева ${ }^{1}$

Дальневосточный федеральный университет, Школа педагогики ДВФУ

Владивосток. Россия

В.С. Чернявская ${ }^{2}$

Владивостокский государственный университет экономики и сервиса

Владивосток. Россия

\title{
Представление педагогов об универсальных учебных действия х при формировании пространственно- временных компетенций учащихся старшей школы
}

\begin{abstract}
Аннотация. В современных условиях пространственно-временная проблематика в рамках естественнонаучной подготовки учащихся старшей школы должна осуществляться в рамках учебного плана на основе формирования интереса к пространству и времени, а также сопутствующего опыта в данной области. При изучении тематики пространства и времени критериями отбора учебно-научного материала должны выступать: 1) значимость понятий о пространстве и времени, а также их составляющих как важных элементов информации, необходимой для изучения последующих понятий и закономерностей; 2) изучение и связь образовательного контекста не только с категориями пространства и времени, но и с пространством-временем как единым целым, изучаемым в курсе физики; 3) возможность применения уже изученного в учебноисследовательской работе и, как следствие, наблюдение объектов и процессов в области пространства-времени с последующим формированием у учащихся пространственно-временных компетенций.
\end{abstract}

Ключевые слова: универсальные учебные действия, пространство, время, пространство-время, компетенции, самораскрытие.

\footnotetext{
${ }^{1}$ Кадеева Оксана Евгеньевна - канд. филос. наук, доцент департамента теории и практики преподавания математики, информатики и естественных наук. ORCID: 00000001-8498-7305; e-mail: kadeeva.oe@dvfu.ru

2 Чернявская Валентина Станиславовна - д-р пед. наук, профессор, профессор кафедры философии и юридической психологии. ORCID: https://orcid.org/0000-0001-66746305; e-mail: valstan13@mail.ru
} 


\title{
O.E. Kadeeva
}

Far Eastern Federal University, FEFU School of Pedagogy

Vladivostok. Russia

\section{V.S. Chernyavskaya}

Vladivostok State University of Economics and Service

Vladivostok. Russia

\section{Teachers' idea of universal educational actions in the formation of spatiotemporal competencies of high school students}

\begin{abstract}
In modern conditions, space-time problems within the framework of natural science training of high school students should be carried out within the curriculum based on the formation of interest in space and time, as well as related experience in this field. When studying the topics of space and time, the criteria for the selection of educational and scientific material should be: 1) the significance of the concepts of space and time, as well as their components, as important elements of information necessary for the study of subsequent concepts and patterns; 2 ) the study and connection of the educational context not only with the categories of space and time, but also with space-time as a whole, studied in the course of physics; 3 ) the possibility of applying what has already been studied in educational and research work and, as a consequence, the observation of objects and processes in the field of space-time with the subsequent formation of space-time competencies in students.
\end{abstract}

Keywords: universal learning activities, space, time, spacetime, competencies, selfdisclosure.

Изложить понятно и доступно естественнонаучные термины, принадлежащие области изучения пространства и времени, обучающимся в старшем звене школы необходимо не на основе проблемы устаревания информации о новых результатах, а на поиске нового в опыте учеников. Поэтому основное внимание следует уделять классическим (традиционным) принципам, идеям, закономерностям, которые актуальны при переходе из одной физической картины мира в другую. Понятия о пространстве и времени в физике относятся к разряду классических. А вот понятие «пространство-время» не является таковым. Следовательно, целью образовательного процесса на уроках физики должно стать не автоматическое восприятие знаний учащимися и традиционная их передача педагогом, а процесс включения интереса и мотивации для формирования у учеников мировоззрения относительно изучения пространства, времени и пространства-времени как единого целого. Таким образом, для формирования у школьников компетенций в области пространственно-временной проблематики и сопутствующих компетенций выделим следующие этапы [1, с. 89].

1. Создать условия для формулировки учащимися классических понятий «пространство» и «время» с последующим переходом к единому понятию «пространство-время», вследствие чего ученики смогут понять и сформулировать категории трансдисциплинарности при изучении понятия пространства- 
времени, а также увидеть его роль и значимость в науке, в социуме, в образовательном процессе и жизнедеятельности человека в целом; смогут сформировать представления о качественных и количественных характеристиках, фундаментальных понятиях и терминах, законах и формулах, которые лежат в основе пространственных, временных и пространственно-временных процессов. В результате вышеперечисленного у учащихся начинает развиваться трансдисциплинарное мышление с компетенциями исследования в области пространства-времени и с основными знаниями в области астрофизики. Далее учащимся можно показать возможности изучения пространства и времени в области макро- и микромира, привести примеры через синергетический подход к исследованию вышеуказанных понятий.

2. В рамках создания активизирующей образовательной среды в области пространственно-временной проблематики акцентировать внимание обучающихся на всех естественнонаучных дисциплинах общеобразовательной школы, таких как физика, биология, химия, география, астрономия. При этом урок необходимо основывать на конкретных примерах с демонстрацией иллюстраций. Тогда учеба будет запоминающейся, интересной и весь учебный процесс сможет простимулировать учащихся к исследовательской, самостоятельной деятельности.

При таком учебном подходе к исследованию пространственно-временных процессов и самих понятий прослеживаются конкретные научные межпредметные связи (таблица).

Способы постановки цели, разработанные М.В. Клариным, при изучении учащимися понятий пространства и времени на уроках физики [7]

\begin{tabular}{|l|l|l|}
\hline $\begin{array}{l}\text { Способ постановки цели } \\
\text { на уроке физики }\end{array}$ & \multicolumn{1}{|c|}{ Примеры целей урока } & $\begin{array}{l}\text { Характер инструментальности, } \\
\text { технологичности способа по- } \\
\text { становки цели на уроке физики }\end{array}$ \\
\hline $\begin{array}{l}\text { Цель как основа изуча- } \\
\text { емого содержания }\end{array}$ & $\begin{array}{l}\text { Изучить понятия пространства, } \\
\text { времени и пространства-времени, } \\
\text { содержание необходимых глав }\end{array}$ & $\begin{array}{l}\text { Формулировка в целом не рас- } \\
\text { крывает понимание конечного } \\
\text { результата }\end{array}$ \\
\hline $\begin{array}{l}\text { Цель как основа деятель- } \\
\text { ности учителя }\end{array}$ & $\begin{array}{l}\text { Ознакомить учащихся с про- } \\
\text { странственно-временными зако- } \\
\text { номерностями в микромире, про- } \\
\text { демонстрировать приемы воспри- } \\
\text { ятия пространства и времени в } \\
\text { механике и электродинамике }\end{array}$ & $\begin{array}{l}\text { Изложение цели в виде данной } \\
\text { формулировки подразумевает }\end{array}$ \\
лишь деятельность учителя
\end{tabular}


Мы позволили себе несколько скорректировать способы постановки цели, указанные М.В. Клариным, поскольку, на наш взгляд, цель должна быть идентифицированной, то есть в ее описании должна быть доказательная база, с помощью которой можно в полном объеме описать ее признаки.

Рассмотрим общие подходы к формированию универсальных учебных действий/базовых компонентов (УУД) по изучению пространства-времени на уроках физики.

Занятия по физике при изучении понятий пространства и времени можно выстроить через $[4,5]$ :

- установление взаимосвязей готовых ценностей в процессе их усвоения. Например, небольшой рассказ учителя о восприятии пространства и времени в космосе и на земле и, как следствие, постановка перед учащимися задачи составить примеры поведения космических и некосмических объектов в пространстве-времени;

- рефлексию как способ самостоятельного формулирования учащимися выводов и оформления итоговых результатов;

- развитие творческой активности учащихся и их личный опыт вследствие саморазвития и исследовательской деятельности с плавным переходом к фазе интеграции личности.

На основе вышеперечисленного выделим следующие компоненты $[2,6]$ :

- целевой компонент. Отражает фундамент освоения учащимися понятий «пространство», «время» и «пространство-время» как всего процесса формирования у них базовых компонентов УУД;

- содержательный компонент. Основывается на таких разделах физики, как «Механика», «Электродинамика» и «Оптика»;

- процессуальный компонент. Описывает содержательную часть формирования УУД при самостоятельной исследовательской деятельности учащихся в пространственно-временной проблематике через мотив «достижение» или «саморазвитие»;

- результативный компонент. Выступает как итоговая составляющая на эвристическом, творческом уровнях и как уровень проверки базовых компонентов УУД через мотив «профессионально-жизненное самоопределение».

Методика освоения понятий о пространстве и времени, а также об едином пространстве-времени по физике с последующим формированием у учащихся естественнонаучных УУД может быть основана на следующих положениях [3, c. 271]:

1. Применяемые в процессе обучения пространственно-временные компоненты должны быть трансдисциплинарны к любому образовательному продукту. В исследовании реализован принцип подбора процесса изучения понятий пространства и времени, а также единого пространства-времени под все виды поставленных целей и задач.

2. Соединение трех разделов физики («Механика», «Электродинамика»и «Оптика») реализует конвергентность за счет собственной внутренней логики изложения каждого раздела, а они в свою очередь внешне соединяются (конвер- 
гируют) в процессе всего учебного процесса на самом уроке и последующих занятиях.

3. Формирование естественнонаучных, в частности пространственновременных, УУД реализуется на каждом уроке в процессе решения учащимися задач или осуществления ими исследовательской деятельности согласно поставленным перед ними условиям реализации процесса освоения пространственновременной проблематики, а также закладки фундамента основ формирования у учащихся соответствующих компетенций.

В качестве основного методического инструмента автор [3] использовала исследовательскую деятельность учащихся, которая позволяет обеспечить формирование пространственно-временных УУД в процессе мировосприятия изучаемых ранее разделов по пространственно-временной проблематике.

В оценке исследовательской работы участвовали учителя физики (16 человек). Им были предложены вопросы следующего характера (представим некоторые из них):

1) в каких разделах физики ими делается упор на изучение понятий пространства, времени и пространства-времени;

2) какие практические знания, представленные учащимся, реализуются в первую очередь через теоретическое восприятие научного материала в процессе самостоятельного нахождения метода, приема и средства без опытной и доказательной базы, а также с мысленным проникновением в сущность пространственно-временных процессов;

3) используют ли они в учебном процессе по физике исследовательскую деятельность путем реализации различных средств и приемов.

Процесс освоения учащимися понятий пространственно-временной проблематики с одновременным формированием естественнонаучных УУД развивает у них научное мышление в ходе решения задач, проведения экспериментов и реализации исследовательской деятельности по физике и астрономии. Реализация методики заложения у обучающихся основ пространственно-временных компетенций позволит не только сформировать весь цикл универсальных учебных действий, но и развить мышление в области пространства-времени; сформировать у обучающихся знания, умения и навыки, связанные с исследовательской и экспериментальной деятельностью о пространстве, времени и пространстве-времени; сформировать научную культуру работы с информацией о пространстве, времени и пространстве-времени; заложить представления о пространстве, времени и пространстве-времени, об их роли в жизни человека и общества; реализовать у обучающихся получение предметных и метапредметных результатов.

Естественнонаучные УУД комплектуются в процессе освоения учащимися разделов механики, электродинамики и оптики, при этом генерируются пространственно-временные компетенции как основа физических и астрофизических восприятий пространства-времени. 
Для этого содержание разделов физики необходимо сделать гибким и универсальным [8, 9], базируясь на технологии:

- многогранности - всеобщности к используемой тематике пространства, времени и пространства-времени в цикле всех естественнонаучных дисциплин;

- трансдисциплинарности - схожести всех понятий, каким-либо образом пересекающихся с понятиями о пространстве, времени и пространстве-времени;

- вариативности - возможности выбора последовательности изучения разделов о пространстве, времени и пространстве-времени в зависимости от возможностей и интересов обучаемых;

- практичности - доказательности через исследовательскую деятельность как главный методический подход к освоению разделов физики;

- объемности (адаптивности) - возможности увеличения числа часов и объема содержания научного учебного материала;

- открытости - возможности добавления новых разделов (например, «Квантовая физика» и «Астрономия»), расширяющих и дополняющих содержание основных разделов, раскрывающих понятия о пространстве, времени и пространстве-времени.

Таким образом, формирование пространственно-временных компетенций у учащихся происходит на протяжении всего учебного процесса (на каждом уроке дисциплин естественнонаучного цикла) в ходе реализации ими исследовательской деятельности, при решении задач, выполнении практикумов и проектной деятельности. Поэтому в процессе решения задач или исследовательской деятельности в соответствии с перечисленными требованиями осуществляются:

- конвергенция содержания разделов «Механика», «Электродинамика» и «Оптика», в результате чего у учащихся формируются основы понимания пространственно-временной проблематики, закладываются навыки исследовательской деятельности в этой области и, самое главное, формируются пространственно-временные компетенции;

- формирование всех видов УУД через их базовые компоненты на протяжении всего учебного процесса.

На основе вышеизложенного можно сделать вывод о том, что формирование пространственно-временных компетенций у учащихся происходит, когда:

1) проблема в области пространства, времени и пространства-времени раскрыта перед учащимися на основе научных положений и в соответствии с теоретически обоснованной гипотезой;

2) обучающиеся могут с легкостью преобразовать действительность об едином пространстве-времени на примере решения задач или при реализации исследовательской деятельности;

3) исследовательскую деятельность сопровождают анализом промежуточных и конечных результатов, извлекая при этом выводы и делая обобщения.

1. Абдурагимова 3. М. Формирование ИКТ-компетентности будущих учителей на занятиях по общей физике: с учетом региональных условий: дис. ... канд. пед. наук: 13.00.02. - Москва, 2013. - 231 с. 
2. Гребенев И.В., Лебедева О.В. Реализация требований ФГОС и методическое мастерство учителя // Педагогика. - 2016. - № 6. - С. 72-79.

3. Гурина Р.В. Подготовка учащихся физико-математических классов к профессиональной деятельности в области физики: дис. докт. пед. наук: 13.00.02. - Москва, 2008. $471 \mathrm{c.}$

4. Данилов О.Е. Методология формирования профессиональной компетентности учителя физики на основе использования им информационных технологий в своей профессиональной деятельности: монография / Министерство образования и науки Российской Федерации, Федеральное государственное бюджетное образовательное учреждение высшего образования «Глазовский государственный педагогический институт имени В.Г. Короленко». - Глазов: ГГПИ, 2017. - 86 с.

5. Демидова М.Ю. Современные подходы к оценке качества естественнонаучного образования в международных и национальных исследованиях // Естественнонаучное образование: проблемы оценки качества: сборник. - Москва: Издательство Московского университета, 2018. - С. 14-41.

6. Кириллова Т.В. Критерии и уровни готовности будущего учителя физики к управлению процессом достижения школьниками предметных образовательных результатов по физике // Проектная деятельность: новый взгляд на образование: сборник трудов Всероссийской научно-практической конференции. - Астрахань: Издательский дом «Астраханский университет», 2018. - С. 112-117.

7. Кларин М.В. Инновационные образовательные практики как инициативы в сфере дополнительного образования детей и молодежи // Этап: Экономическая теория, анализ, практика. - 2019. - № 6. - С. 31-48.

8. Лебедева О. В., Пономарев С. М. Современные технологии в организации исследовательской работы школьников // Преподавание физико-математических и естественных наук в школе. Традиции и инновации: материалы Всерос. науч.-метод. конф. - Нижний Новгород: ННГУ, 2017. - С. 89, 90.

9. Лебедева О.В., Гребенев И. В. Подготовка будущего учителя физики к проектированию и организации учебно-исследовательской деятельности // Педагогическое образование в России. - 2018. - № 5. - С. 98-104.

\section{Транслитерация}

1. Abduragimova Z.M. Formirovanie IKT-kompetentnosti budushchih uchitelej na zanyatiyah po obshchej fizike: s uchetom regional'nyh uslovij: dis. ... kand. ped. nauk: 13.00.02. Moskva, 2013. - $231 \mathrm{~s}$.

2. Grebenev I. V., Lebedeva O. V. Realizaciya trebovanij FGOS i metodicheskoe masterstvo uchitelya // Pedagogika. - 2016. - № 6. - S. 72-79.

3. Gurina R. V. Podgotovka uchashchihsya fiziko-matematicheskih klassov k professional'noj deyatel'nosti v oblasti fiziki: dis. dokt. ped. nauk: 13.00.02. - Moskva, 2008. - $471 \mathrm{~s}$.

4. Danilov O. E. Metodologiya formirovaniya professional'noj kompetentnosti uchite-lya fiziki na osnove ispol'zovaniya im informacionnyh tekhnologij $\mathrm{v}$ svoej professional'noj deyatel'nosti: monografiya / Ministerstvo obrazovaniya i nauki Rossijskoj Federacii, Federal'noe gosudarstvennoe byudzhetnoe obrazovatel'noe uchrezhdenie vysshego obrazovaniya «Glazovskij gosudarstvennyj pedagogicheskij institut imeni V. G. Korolenko». - Glazov: GGPI, 2017. - $86 \mathrm{~s}$.

5. Demidova M. Yu. Sovremennye podhody k ocenke kachestva estestvennonauchnogo obrazovaniya v mezhdunarodnyh i nacional'nyh issledovaniyah // Estestvennonauchnoe 
obrazovanie: problemy ocenki kachestva: sbornik. - Moskva: Izdatel'stvo Moskovskogo universiteta, 2018. - S. 14-41.

6. Kirillova T. V. Kriterii i urovni gotovnosti budushchego uchitelya fiziki k upravleniyu processom dostizheniya shkol'nikami predmetnyh obrazovatel'nyh rezul'tatov po fizike // Proektnaya deyatel'nost': novyj vzglyad na obrazovanie: sbornik trudov Vserossijskoj nauchno-prakticheskoj konferencii. - Astrahan': Izdatel'skij dom «Astrahanskij universitet», 2018. - S. 112-117.

7. Klarin M. V. Innovacionnye obrazovatel'nye praktiki kak iniciativy v sfere do-polnitel'nogo obrazovaniya detej i molodezhi // Etap: Ekonomicheskaya teoriya, analiz, praktika. - 2019. № 6. - S. 31-48.

8. Lebedeva O.V., Ponomarev S. M. Sovremennye tekhnologii v organizacii issledova-tel'skoj raboty shkol'nikov // Prepodavanie fiziko-matematicheskih i estestvennyh nauk v shkole. Tradicii i innovacii: materialy Vseros. nauch.-metod. konf. - Nizhnij Novgorod: NNGU, 2017. - S. 89, 90

9. Lebedeva O. V., Grebenev I. V. Podgotovka budushchego uchitelya fiziki k proektirovaniyu i organizacii uchebno-issledovatel'skoj deyatel'nosti // Pedagogicheskoe obrazovanie v Rossii. - 2018. - № 5. - S. 98-104.

() О.Е. Кадеева, 2021

(C) В.С. Чернявская, 2021

Для цитирования: Кадеева О.Е., Чернявская В.С. Представление педагогов об универсальных учебных действиях при формировании пространственно-временных компетенций учащихся старшей школы // Территория новых возможностей. Вестник Владивостокского государственного университета экономики и сервиса. - 2021. - Т. 13, № 4. C. $223-230$.

For citation: Kadeeva O.E., Chernyavskaya V.S. Teachers' idea of universal educational actions in the formation of spatiotemporal competencies of high school students, The Territory of New Opportunities. The Herald of Vladivostok State University of Economics and Service, 2021, Vol. 13, № 4, pp. 223-230.

DOI https://doi.org/10.24866/VVSU/2073-3984/2021-4/223-230

Дата поступления:

18.11.2021
Одобрена после рецензирования: 19.11.2021
Принята к публикации: 22.11.2021 